\title{
Modelagem em artes na educação infantil: a cultura indígena como estratégia lúdica de aprendizagem
}

\author{
Modeling in arts in childhood education: indigenous culture as a learning \\ learning strategy
}

Soraia Jordão Souza

Désirée Gonçalves Raggi

\begin{abstract}
Resumo: Este artigo objetiva compreender como as atividades lúdicas, como a modelagem de objetos da cultura indígena potencializam o ensino de Artes na Educação Infantil, em uma escola de Educação Infantil de Presidente Kennedy. Apresenta-se os princípios e concepções advindos do Referencial Nacional da Educação Infantil que descreve a necessidade de cuidados, aprendizagem lúdica e promoção de atitudes e valores para participação social e cultural da criança. A produção se baseia em Vygotsky (2000), para explicar o desenvolvimento cognitivo e comportamental advindo das relações sociais e Oliveira (2018), que discute a utilização da modelagem no ensino de Artes como recurso pedagógico na educação infantil. Parte da premissa que a modelagem utiliza objetos da cultura indígena traz uma proposta pedagógica que possibilita o desenvolvimento humano, considerando que os sujeitos se tornam capazes de desenvolver cognitivamente e socialmente pelo campo da arte e pela experiência estética. Este estudo é classificado como de abordagem qualitativa, de cunho descritivo e pesquisa-intervenção. Foram investigados três professores da Educação Infantil: dois regentes de sala e o professor da disciplina de Artes de duas turmas do $2^{\circ}$ Período. A observação foi realizada com aplicação de uma Sequência didática intitulada: "Modelando a cultura dos índios, revelando nossa história", que foi executada pelo professor regente e pelo professor da disciplina de Artes. Os resultados da pesquisa permitem concluir que o trabalho com modelagem em argila, de objetos da cultura indígena, como estratégia usada no ensino de Artes, auxilia no desenvolvimento integral da criança, constatado pelo estimulo à imaginação, sensibilidade, movimentos, gestos, criatividade, socialização, possibilitando ainda a sensação de pertencimento ao mundo e a valorização da cultura indígena.
\end{abstract}

Palavras-chave: Modelagem; Artes; Atividades Lúdicas com argila; Cultura indígena; Educação Infantil.

Abstract: This article aims to understand how playful activities, such as the modeling of objects of indigenous culture, enhance the teaching of Arts in Early Childhood Education, in a preschool school in Presidente Kennedy. The principles and concepts arising from the National Reference for Early Childhood Education are described, which describes the need for care, playful learning and the promotion of attitudes and values for the child's social and cultural participation. The production is based on Vygotsky (2000), to explain the cognitive and behavioral development arising from social relations and Oliveira (2018), who discusses the use of modeling in the teaching of Arts as a pedagogical resource in early childhood education. Part of the premise that modeling uses objects from indigenous culture brings a pedagogical proposal that enables human development, considering that subjects become capable of developing cognitively and socially through the field of art and aesthetic experience. This study is classified as a qualitative approach, descriptive and research-intervention. Three teachers of Early Childhood Education were investigated: two classroom conductors 
and the teacher of the Arts discipline of two classes of the 2nd Period. The observation was carried out with the application of a didactic sequence entitled: "Modeling the culture of the Indians, revealing our history", which was carried out by the regent teacher and by the professor of the Arts discipline. The results of the research allow to conclude that the work with modeling in clay, of objects of the indigenous culture, as strategy used in the teaching of Arts, helps in the integral development of the child, verified by stimulating the imagination, sensitivity, movements, gestures, creativity, socialization, also allowing the feeling of belonging to the world and the appreciation of indigenous culture.

Keywords: Modeling; Arts; Playful activities with clay; Indigenous culture; Child education.

\section{Introdução}

Atividades lúdicas podem alcançar desenvolvimento global e uma visão de mundo mais realista. Por meio da descoberta e da criatividade, as crianças podem se expressar, analisar, criticar e transformar a realidade. Se usada e compreendida de maneira adequada, a educação respaldada em atividades lúdicas pode ajudar a melhorar as qualificações dos alunos ou o nível de ensino do treinamento crítico, ou pode redefinir valores e melhorar $o$ relacionamento das pessoas com a sociedade (DALLABONA; MENDES, 2004).

Além disso, a utilização do lúdico é agradável e bem adequado à faixa etária das crianças, as quais permitem que a aprendizagem ocorra no seu mundo, enquanto formação humana, já que, durante uma atividade lúdica, as crianças aprendem novas maneiras de conviver com os colegas, o que thes possibilita uma vida em sociedade. Em se tratando da educação infantil, as atividades lúdicas envolvem jogos e brincadeiras como a modelagem (ARANTES; BARBOSA, 2017).

Nesse contexto, o objetivo geral deste estudo é compreender como as atividades lúdicas, como a modelagem de objetos da cultura indígena, potencializam o ensino de Artes na Educação Infantil numa escola de Educação Infantil do Município de Presidente Kennedy.

A pesquisa foi realizada na escola EMEIEF Vilmo Ornelas Sarlo pertencente a Rede Municipal de Presidente Kennedy, uma cidade do sul do estado do Espírito Santo, Brasil. Trata-se de uma escola urbana que atende 877 alunos, divididos em 142 na Educação Infantil (Pré-escola), 288 nos anos iniciais do Ensino Fundamental, 323 nos anos finais do Ensino Fundamental e 
124 alunos na Educação de Jovens e Adultos. Contam com o atendimento de 49 professores com licenciatura e pós-graduação na área em que atuam.

O estudo se justifica, pois na Educação Infantil as práticas pedagógicas que incluem o lúdico para o ensino de artes e expressões artísticas e culturais possibilitam o desenvolvimento motor, perceptivo e social, sendo o desenho, a pintura e a modelagem exemplos de atividades que as crianças realizam. Ocorre que muitas das produções das crianças acabam sendo cópias dos formatos pré-estabelecidas pelos adultos (OLIVEIRA, 2008).

A arte segundo Vygotsky (2009) é o movimento de reflexão do ser humano sobre os pensamentos emocionais que nos tocam, a criação e o entretenimento de todo o ambiente social macroscópico da complexidade humana, é um método de ensino para perceber e confortar a realidade e a depressão humana. Segundo o autor, esse movimento de compreensão da arte como ferramenta de construção humana marca a formação epistemológica e sensível do processo de construção da inteligência mental infantil.

Então, a relevância da pesquisa está baseada na necessidade de os profissionais da educação compreenderem as crianças como sujeitos das relações socioculturais, que não somente reproduzem, mas criam cultura. Isso ocorre por meio de produções artísticas na linguagem da modelagem com argila, pela forma intencional e pelo desenvolvimento da imaginação que essa metodologia lúdica possibilita à criança.

\section{Ensino de artes e desenvolvimento integral da criança}

O ensino de Artes é importante para a criança, pois possibilita seu desenvolvimento expressivo, visão poética e criatividade, ao despertar a sensibilidade para observar o mundo com outro olhar. Desde cedo, a imaginação da criança deve ser trabalhada, tendo as artes como aliada nesse processo, pois, para a criança, a arte é uma maneira de se expressar, é uma forma de lidar com a realidade, por isso demonstra tanto interesse em brincar e desenhar, é assim que demonstra seus desejos e medos (COLETO, 2010).

Por volta dos dois anos de idade, a criança começa seus rabiscos, demonstrando, com forma gráfica, sonora ou corporal, o que sente e entende 
do ambiente em que está inserida. Assim, a criança valoriza mais a construção, o processo, do que o resultado final. Na grafia, faz rabiscos livres, traços horizontais, verticais e inclinados, após círculos, mesmo sem atribuir sentido para esses rabiscos, para a criança, é uma forma de comunicação e expressão de ideias, sentimentos, por isso, as crianças devem ser estimuladas a rabiscar, posteriormente, esses traços vão levar à escrita (COLETO, 2010).

As Diretrizes Curriculares Nacionais para a Educação Infantil apresentam a importância da Arte, a partir das várias manifestações, como práticas pedagógicas da Educação Infantil, com o objetivo de ensejar vivências e experiências que possibilitem a aquisição de conhecimento, despertando sentidos e promovendo, pela ludicidade, o desenvolvimento integral da criança.

Em consonância com as Diretrizes Curriculares Nacionais para a Educação Infantil, Gaio (2015) auxilia na compreensão das aprendizagens traçando um paralelo entre os comportamentos expressos pelas crianças e seus respectivos significados. Quando a se expressa por meio de desenhos, desenvolve a criatividade e outras potencialidades, uma vez que aprimora sua compreensão da realidade. As expressões grafadas no papel a induzem a viver, inventar e reinventar explicações para situações do cotidiano (GAIO, 2015).

De acordo com Gaio (2015), a dança se manifesta como expressão por meio do movimento corporal. Esta atividade permite que a criança descubra [...] sua capacidade de descobrir o espaço, interagir com outras crianças, realizar movimentos e gestos com ritmo, equilíbrio e coordenação, e demonstrar seus sentimentos.

O autor defende atividades musicais no espaço da educação infantil, pois desde a gestação, a criança tem contato com a música, por isso o trabalho pedagógico que envolve a música, incentiva a percepção, curiosidade, sensibilidade, atenção, imaginação, organização de ideias e fantasia da criança (GAIO, 2015).

Trazendo o contexto da pintura e da imaginação, a criança se desenvolve em aspectos voltados aos sentimentos, emoções, vivências, sensibilidade, capacidade intelectual, física, perceptiva, gosto estético e 
socialização, já que, com a pintura, expõe não só traçados, mas sua vivência e conclusões que tenha percebido do mundo em que vive (GAIO, 2015).

Gaio (2015) indica acrescentar atividades como contação de histórias da literatura infantil, pois permitem à criança o desenvolvimento do imaginário, o gosto e prazer pela leitura, pela compreensão do mundo, produzindo a capacidade futura de ser um bom leitor. A literatura infantil através dos contos e poesias, pela composição e sonoridade, contribui para o desenvolvimento inventivo e expressão da criança. Isso, isso por meio da linguagem, sons semelhantes, ritmo, comparações e oposições de sentido.

Os jogos teatrais também podem ser trabalhados individualmente ou coletivamente, possibilitando relacionamentos interpessoais, a inteligência, afetividade, imaginação, dramatização, pensamento e fala, pelo lúdico, já que é uma proposta que visa à aprendizagem pela recriação, problematização e reflexão de vivências de situações cotidianas (GAIO, 2015).

Nesse sentido, as atividades lúdicas propostas possibilitam a [...] indivisibilidade das dimensões expressivo motora, afetiva, cognitiva, linguística, ética, estética e sociocultural da criança", como orientado nas DCNEI (2010, p. 19)

Diante do quadro apresentado, é possível notar que o ensino de Artes na educação infantil possibilita o desenvolvimento integral da criança, ao incentivar a imaginação, sensibilidade, movimentos, gestos, criatividade, socialização, reprodução de situações reais. Potencializa, ainda, a cognição, o pensamento, além da capacidade de levar a criança a perceber o mundo e a experimentar sentimentos de ternura, simpatia, empatia. Comente aqui como esse quadro foi utilizado na sua análise.

A Modelagem com Argila e sua Influência no Desenvolvimento Integral da Criança

Os processos cognitivos e psicológicos se dividem em dois níveis, o interpsicológico e intrapsicológico: o primeiro tem como base as relações sociais, onde as crianças aprendem pela convivência com as outras pessoas (sociedade), já o segundo tem referência no nível individual, a aprendizagem ocorre a partir dos conhecimentos que as crianças já adquirem, desde o 
nascimento (VYGOTSKY, 2010). Para este autor, o aprendizado pode ser compreendido como um processo externo, que pouco está envolvido no aprendizado.

Não existe um único nível de desenvolvimento para Vygotsky, o primeiro nível é chamado de desenvolvimento efetivo da criança, ou seja, "[...] as funções psicointelectuais da criança que se conseguiu como resultado de um específico processo de desenvolvimento já realizado" (VYGOTSKY, 2010, p.111).

O segundo nível é chamado de desenvolvimento potencial. Na teoria Vygotskyana, o desenvolvimento é fruto de uma gênese social, que acontece de fora para dentro, com auxílio da cultura. A aprendizagem e o desenvolvimento não ocorrem como um processo único. O autor atribui valor à aprendizagem somente quando ela mesma é uma fonte de desenvolvimento. Vygotsky (2010, p. 212) considera que a aprendizagem "[...] é útil quando se move à frente do desenvolvimento. Ao fazê-lo, ela impele ou desperta toda uma série de funções que estão em fase de maturação, repousando na zona de desenvolvimento proximal".

A teoria do desenvolvimento potencial de Vygotsky (2010) facilita a compreensão do progresso cognitivo humano, que defende o caminho que a criança perfaz para assimilar funções em processo de amadurecimento, as quais serão consolidadas, chegando ao nível de desenvolvimento real. A criança pode precisar da ajuda de um adulto em uma atividade - zona de desenvolvimento proximal, após será capaz de realizar a ação sozinha, alcançando a zona de desenvolvimento real. O avanço no estado do desenvolvimento mental da criança, afetivo ou potencial, só pode ser determinado, ao ser relacionado como o mínimo de dois níveis (VYGOTSKY, 2010).

Portanto, a modelagem como estratégia de ensino de Artes na Educação Infantil, através das interações sociais, é marcada pela subjetividade em consequência da relação que cada criança constitui com sua produção artística, além do sentimento de reconhecimento e pertencimento a uma sociedade. Isso nos leva a entender o ensino das Artes pela modelagem e seu 
auxílio direto à formação humana pela vivência da criança, como afirma Diehl (2008, p. 1521): “[...] as possibilidades da linguagem tridimensional, proporcionaram aos educandos produzirem, por meio da arte numa ação perceptiva que implica sentir e expressar a partir do material".

\section{A modelagem como processo de valorização da cultura indígena e o desenvolvimento integral da criança}

As DCNEI orientam para a necessidade de organização de tempos, espaços e materiais da escola, com o propósito de consolidação dos objetivos e propostas pedagógicas das instituições de Educação Infantil. Com isso, a criança precisa ter condições para realizar a aprendizagem coletiva, cabendo ao professor o planejamento de atividades e organização de materiais, espaços e tempos que assegurem. "A apropriação pelas crianças das contribuições histórico-culturais dos povos indígenas, afrodescendentes, asiáticos, europeus e de outros países da América" (BRASIL, 2010, p.20).

Nesse sentido, é importante que a escola contemple, em sua proposta curricular, elementos históricos e conceituais relacionados aos grupos sociais que são alvo de preconceito e tem seus direitos postos em questão. É imprescindível que os educadores realizem práticas escolares voltadas para essa temática, a fim de que a criança saiba valorizar a diversidade ética e cultural presente na sociedade. Portanto, essa estratégia tende a mitigar 0 preconceito racial tão evidente no cenário atual brasileiro.

Santiliano (2018) salienta que os povos originários que viviam no sul do Estado do Espírito Santo e norte do estado do Rio de Janeiro, mais especificamente nas regiões litorâneas, eram os índios Goitacazes, Puris e Botocudos. Os Goitacazes também eram chamados de goitacás e guaitacás, encontrados pelos europeus no baixo Itabapoanna, no ano de 1540, a tradução do nome Goitacazes significa corredor, ou nadador. Antes da chegada dos europeus, eles haviam descido do Paraíba do Sul, atualmente município de Campos dos Goitacazes, e chegado ao litoral sul do Espírito Santo, alcançando os municípios de Anchieta e até Guarapari, onde atacaram alguns 
estabelecimentos portugueses, voltando para o litoral norte fluminense, onde guerrearam e expulsaram os europeus.

A Modelagem como Instrumento para Conhecimento e Valorização da Cultura Indígena

O conhecimento das raízes indígenas pelas crianças reside no fato de que possam valorizar as diferenças existentes na sociedade, justamente como propõem as Diretrizes curriculares Nacionais para Educação Infantil, pois toda criança precisa ter ciência da diversidade que constitui a sociedade. Cabe, então, à escola a função de operacionalizar propostas curriculares que incentivem a aquisição de tais conhecimentos (BRASIL, 2010).

Assim, na tentativa de trazer à baila os valores culturais do povo indígena, opta-se por desenvolver processos pedagógicos focados em sua riqueza cultural, utilizando a disciplina de Artes. Dessa forma, as crianças poderiam compreender as diferenças e os vários olhares de mundo e, sobretudo, desenvolver o respeito com as diversidades culturais e conferir-lhe a importância merecida. A modelagem como estratégia de ensino pode ser utilizada com esse objetivo, ao reproduzir objetos, modos de vida e a cultura indígena, utilizando as interações sociais para formar ideias, valores e atitudes.

A coleta de argilo-minerais às margens dos rios era papel das índias, que manuseavam uma mistura de elementos orgânicos e inorgânicos e produziam potes, gamelas, jarros, esculturas, vasos e instrumentos, todos apresentando linguagens artísticas, que refletiam as características da tribo, algumas simples e outras mais elaboradas (MENDES, 2016).

A utilização da modelagem com as crianças na educação infantil através da construção de objetos indígenas propicia a reflexão sobre o processo de transformação, textura, temperatura, resistência, forma e plasticidade da argila. Mais que isso, possibilita o conhecimento e a valorização da cultura indígena, pelas suas formas de expressão artísticas, interação da criança com os seus pares, que levam a releituras, debates, comentários, discussões sobre o trabalho manual e o reconhecimento da sua contribuição para nossas vidas e história. 


\section{Metodologia}

Este estudo é classificado como de abordagem qualitativa, de cunho descritivo e pesquisa-intervenção, uma vez que foi implementado um elenco de ações que permitiram a interação da pesquisadora com o objeto pesquisado (a modelagem com argila no ensino de Artes). Tal dinâmica determinou os caminhos da pesquisa, por meio da produção em grupo. Essa metodologia foi essencial para realização do estudo, já que a intervenção se articula à pesquisa para permitir, analisar e entender a relação entre teoria/prática na instituição e aplicação do conhecimento. Como descreve Rocha (2003): "na pesquisa-intervenção, não visamos à mudança imediata da ação instituída, pois a mudança é consequência da produção de uma outra relação entre teoria e prática, assim como entre sujeito e objeto" (ROCHA, 2003, p. 73).

Foram investigados três professores da Educação Infantil: dois regentes de sala e o professor da disciplina de Artes de duas turmas do $2^{\circ}$ Período, com o total de 50 alunos com idade entre 4 e 5 anos, pertencentes à Escola Municipal de Educação Infantil e Ensino Fundamental Vilmo Ornelas Sarlo, vinculada à Rede Municipal de Presidente Kennedy-ES. Essa escolha se deu pelo critério de conveniência, pela facilidade de acesso aos alunos e professores, já que se atua na escola, campo da pesquisa.

A observação foi realizada com aplicação de uma Sequência didática intitulada: "Modelando a cultura dos índios, revelando nossa história", que foi executada pelo professor regente e pelo professor da disciplina de Artes. Nesse processo pedagógico, foram trabalhados os seguintes elementos: Pluralidade Cultural; Discriminação e preconceito; História, cultura, músicas indígenas; Valores éticos; Identidade e autonomia e Interações sociais, com o objetivo de fortalecer o desenvolvimento integral das crianças.

Assim, opta-se pela utilização do grupo focal, como recurso para coleta de informações necessárias à complementação dos dados obtidos pela observação sistemática da participação das crianças, no trabalho com a modelagem de objetos indígenas com argila, no ensino de Artes. 


\section{Discussão dos resultados}

As duas técnicas de investigação forneceram dados relevantes para construção desta análise. Assim serão discutidas separadamente, para, no final, construir-se-á a análise, estabelecendo um entrelaçamento entre os dados produzidos nos dois momentos (nossas observações) e nas discussões do grupo focal, em diálogo com os teóricos que fundamentaram a pesquisa.

\section{Observações}

As observações foram realizadas na turma do $2^{\circ}$ Período da Pré-escola durante o desenvolvimento das intervenções apresentadas, constituídas em forma da Sequência didática intitulada: "Modelando a cultura dos índios, revelando nossa história", onde foram trabalhos.

Nessas atividades, as crianças puderam conhecer diversos aspectos da cultura indígena, tais como seus hábitos alimentares, moradia, atividade de caça e pesca, suas danças, músicas, instrumentos musicais (tambores, flautas, chocalho e outros), vestimentas, artesanatos (cestos, colares, esculturas, pinturas corporais e adornos).

No roteiro de observação, definiram-se alguns parâmetros indicadores de aprendizagem colaborativa, que foram analisados a partir da estratégia pedagógica utilizada e encontram-se sintetizados nos quadros que se seguem. Essa síntese permite uma visão global dos resultados obtidos e facilita a compreensão e a discussão.

Na primeira etapa da Sequência didática, foi apresentado às crianças, um vídeo chamado "nossos índios", sobre a História dos índios, no qual as crianças observaram onde viviam, como comiam, se vestiam e até o que caçavam para se alimentar. Nessa ação, os alunos participaram ativamente, depois de apresentados os vídeos, fotos e danças indígenas. Com facilidade, associaram o conhecimento obtido a sua realidade, ao contar fatos e história que ouviram e vivenciaram fora da escola.

O vídeo apresentado: "Nossos índios" localiza-se no link: https://www.youtube.com/watch?v=64MISgBIr9A., e tem por objetivo iniciar a construção das ideias sobre a cultura indígena. Após sua apresentação, foi iniciada uma roda de conversa, que estimulou as manifestações das crianças 
sobre o enredo da história, como os índios viviam, comiam, moravam, caçavam, se alimentavam e vestiam.

Com facilidade, associaram o conhecimento obtido à sua realidade, ao contar fatos vivenciados e história ouvidas fora da escola. Uma das crianças destacou que considera os índios: "[...] muito fortes, pois vivem na floresta, caçam bichos para comer e pescavam peixes", outra criança acrescentou que: "ouvi muitas histórias dos índios, eles moravam na floresta, antes da gente".

$\mathrm{Na} 2^{\mathrm{a}}$ etapa, as crianças tiveram a oportunidade de observar, e construir, instrumentos musicais e vestimentas, como também reproduzir os ritmos e danças indígenas. Nesse momento de interação, as crianças demonstraram surpresa, ao perceberem que os chocalhos reproduziam sons e ritmos, bem como a alegria ao se perceberem autores desses sons a partir dos instrumentos. Foi perceptível sua satisfação ao se vestirem com roupas indígenas. Essas atividades permitiram criar fantasias, aumentou o entusiasmo para conhecer e participar das danças indígenas, revelando a sensação de pertencimento ao grupo e à cultura.

Ao ouvirem uma música ou perceberem um instrumento indígena, relatavam com rapidez que pertenciam aos índios, demonstrando que compreenderam que a cultura indígena faz parte da diversidade cultural, justamente como propõem as Diretrizes Curriculares Nacionais para a Educação Infantil, quando determina que a escola deve proporcionar situações didáticas, nas quais as crianças possam conhecer suas raízes indígenas, para respeitar diferenças sociais (BRASIL, 2010).

Ao participarem da dança com músicas indígenas, como ilustra a Figura 1 , reproduziam os ritmos assistidos nos vídeos. Tomaram a inciativa de pegar o chocalho construído por eles próprios, sem nenhuma intervenção da professora. Nessa atividade de dança, manifestação artística e lúdica da cultura indígena, foi possível observar a interação entre o grupo, o que demonstra o reconhecimento da cultura indígena. Segundo Chiesa (2004), a linguagem artística e lúdica como estratégia de aprendizagem facilita a comunicação entre as crianças, troca de experiência, interação, socialização, autonomia e sensação de pertencimento a um grupo ou sociedade. 
$\mathrm{Na} 3^{\mathrm{a}}$ etapa da Sequência didática, os professores explanaram sobre a forma como os índios fabricaram suas peças artesanais, como eram elaborados os cestos, colares, esculturas, pinturas corporais e adornos. Feito isso, solicitaram que as crianças fizessem desenhos sobre a vida dos índios, os objetos que utilizavam ou suas moradias. As crianças, no percurso da confecção de desenhos, utilizaram a grafia livre para expressão dos conhecimentos obtidos, algumas delas optaram por desenhar colares relacionando-os aos que costumavam ser usados pela mãe ou tia, remetendo à presença da cultura indígena no nosso cotidiano. Enquanto outras desenharam o que chamavam de "casa dos índios", as ocas, seus desenhos retratavam índios alegres dançando, caçando e pescando.

Os desenhos realizados pelas crianças demonstram a compreensão de que adquiriram conhecimentos da cultura indígena e sua importância para toda a sociedade. Ao pintar um desenho, uma criança destacou que: "[...] meu pai gosta de pescar como os índios, para a gente também comer peixe", já outra criança afirmou: "Professora, por isso tem o Dia do índio, ele é tão importante". Relatos assim demonstram que as atividades despertaram a percepção sobre a importância dos povos indígenas, e que seus hábitos compões nossas raízes culturais.

Essas atividades permitiram o aprofundamento das reflexões abordadas por Bergamaschi e Medeiros (2010) sobre a falsa ideia trazida pelas comemorações pontuais ocorridas no dia do índio, que em nada colabora para a valorização desta cultura. Essa prática, largamente adotada nos espaços escolares, foi disseminada sem o devido aprofundamento a respeito das questões que perpassaram a colonização do povo indígena, escondendo por detrás de lastros romantizados toda carnificina produzida pelos colonizadores e traduzindo as jovens gerações apenas o que não denuncia a imagem dos portugueses durante as invasões.

$\mathrm{Na} 4^{\mathrm{a}}$ etapa as crianças modelaram, com argila, instrumentos musicais, de caça, adornos, moradia e vestimentas, após o quê, as crianças demonstraram seus conhecimentos, pois, livremente, escolheram modelar moradias, colares, chocalhos, arco e flecha, panelas, tambores, lanças e 
cocares, utilizando as mãos e interagindo com os colegas, dando ideias, participando e até questionando sobre suas escolhas e obras. Para Mendes (2016), através da modelagem, em argila, de objetos que fazem parte da cultura indígena, a criança observa as manifestações artísticas e culturais, refletem sobre a cultura indígena presente no seu cotidiano, o que desperta nelas, valores sociais e respeito às diferenças.

Com a modelagem com argila, a aprendizagem aconteceu tendo como pressuposto a ludicidade, interação, contextualização e o sentido dos conhecimentos adquiridos. Enquanto as crianças modelavam, era possível identificar o brilho no olhar em participar desses momentos lúdicos e por conhecer, ainda mais, a cultura indígena. Como defende Vygotsky (2010), ao associar o desenvolvimento da criança a fatores psicológicos, sua história e organização social, movimentam-se as relações sociais, vez que a crianças aprendem pela convivência com as outras pessoas.

Como produto final, realizou-se uma apresentação feita pelas crianças dos objetos indígenas construídos por meio da modelagem, para que outras turmas da Educação Infantil pudessem ter acesso à cultura material, o que favoreceu aos participantes das oficinas explicarem cada objeto e, assim, praticarem a socialização com seus pares, como forma de valorizar a diversidade. Os materiais confeccionados através da modelagem com argila foram produzidos pelas crianças, que se sentiram participantes ativos do processo de produção do conhecimento e oportunizou a partilha desses saberes com outras turmas da Educação Infantil. Observou-se o interesse que esses objetos despertaram nas crianças que interagiam com os autores da modelagem, quando não conseguiam identificá-los.

Dessa forma, os objetivos previstos na sequência didática foram alcançados, pela oportunidade ofertada às crianças de conhecer e reconhecer características, danças, alimentos e objetos que fazem parte da cultura indígena, facilitando pelas formas de expressão artísticas a interação com seus pares, que levam a releituras, debates, comentários, discussões sobre as produções manuais, além da sensação de valorização da cultura indígena. 
Grupo focal

A técnica do grupo focal foi utilizada com o objetivo de colher informações sobre o aprendizado das crianças, com base nas percepções dos professores sobre a utilização da modelagem de objetos indígenas com argila, no ensino de Artes. Os dados irão complementar as conclusões extraídas da observação das crianças, realizada durante a aplicação da Sequência didática.

Esse grupo contou com a participação de três professores das duas turmas do $2^{\circ}$ Período que formam os sujeitos da pesquisa, ou seja, dois regentes de sala e um da disciplina de Artes. Foi realizada uma reunião, para a aplicação das perguntas direcionadas, para que os professores respondessem de forma espontânea sobre: a Artes enquanto disciplina que favorece a formação humana da criança; A modelagem como recurso didático lúdico que propicia o desenvolvimento da criança em fatores cognitivos, culturais, psicomotores e sociais; A utilização da modelagem de objetos indígenas pelos professores em suas aulas, favorecendo a valorização da cultura indígena; A importância de atividades que apresentam a história e cultura dos diversos grupos, que formam a sociedade brasileira.

A sessão do grupo focal trouxe os seguintes resultados: os professores acreditam que os conhecimentos de Artes são fundamentais e afirmam que vêm sendo utilizados na escola para favorecer a formação humana das crianças. A Professora "A" mencionou que:

[...] a criança tem a oportunidade de expor os seus conhecimentos, adquiridos em casa, na escola, com isso pode aprimorar sua criatividade. Na escola a disciplina possibilita a aprendizagem prazerosa e trabalho em grupo, onde até o aluno que não consegue interagir, se solta e de uma ou outra forma conseguem expor o que aprenderam (Professora A, 2019).

A Professora "B" considera que essas atividades "[...] ajudam a minimizar a timidez, estimular a criatividade e memorização, aprimora o trabalho em equipe e possibilidade do improviso, além de despertar o interesse por textos de autores variados". Por sua vez, a Professora "C" acrescentou que as crianças já vêm de uma "cultura onde vivem com a disciplina, podem expor seus conhecimentos e cultura vivida, na escola aprendem em trabalhar em equipe e no individual com criatividade". 
As professoras foram unânimes em reconhecer a contribuição da disciplina de Artes para formação humana e que a escola tem trabalhado com essa proposta. Destacaram que 0 trabalho com artes possibilita a aprendizagem de forma prazerosa, estimulando a criatividade, a memorização e o interesse pela literatura, possibilitando o trabalho em equipe, pois diminui a timidez da criança, além de despertar o interesse pela partilha de conhecimentos trazidos de casa.

Essas opiniões se comprovaram nas observações em momentos de práticas das intervenções descritas no item anterior, ou seja, quando as crianças demonstraram respeito pelas regras de convívio, expressaram ideias e sentimentos, socializaram com seus pares no trabalho em grupo e associaram o conhecimento obtido a sua realidade, ao contar fatos e histórias que ouviram, e viveram, fora da escola. Essas conclusões também foram discutidas nas Diretrizes Curriculares Nacionais para a Educação Infantil, ao garantirem que a disciplina de Artes deve partir da vivência e das experiências, para despertar o conhecimento pelos sentidos, utilizando, como recurso, a ludicidade, visando ao desenvolvimento integral da criança (BRASIL, 2010).

Ao serem questionados sobre a utilização da modelagem, como recurso didático lúdico e se este recurso propicia o desenvolvimento da criança, nos aspectos cognitivos, culturais, psicomotores e sociais, todos os professores afirmaram que utilizam essa estratégia, em suas práticas pedagógicas e acreditam que favorecem a formação da criança, nos aspectos citados.

Em relação à modelagem como estratégica lúdica, que propicia o desenvolvimento da criança, os professores elencaram os seguintes aspectos: estimula a criatividade, a expressão de sentimentos, saberes, habilidades sensoriais, coordenação motora fina, habilidades e contribui para a formação da criança, e isso se dá pelo caráter lúdico que confere prazer ao ato de aprender. Essas manifestações encontram respaldo teórico em Villa (2013), para quem a modelagem é uma linguagem artística lúdica, que propicia o despertar dos sentidos do corpo do indivíduo e Giannotti (2008), ao mencionar essa estratégia lúdica como propulsora do desenvolvimento motor, criativo e emocional da criança. 
Interessou-nos conhecer as opiniões dos professores sobre a modelagem de argila para a criação de objetos indígenas, ou seja, se consideram que tais práticas favorecem a valorização da cultura desses povos. Todos afirmaram que sim. A professora "A" enfatizou que ao criar os "objetos, as crianças podem demostrar no concreto o seu conhecimento, na modelagem mostram o respeito a cultura, através dos mínimos detalhes, as crianças são detalhistas e realmente aprendem o que Ihes foi ensinado".

Baseados nas manifestações obtidas no grupo focal, é possível considerar que essa estratégia pedagógica propicia às crianças desenvolver valores como, o respeito à cultura indígena, pois passam a conhecer suas características, tradições, costumes e objetos por meio de uma vivência lúdica.

A pesquisa contribuiu para a assimilação de novas ideias e percepções em torno da Educação Infantil e do ensino de Artes, pois na minha trajetória profissional, considerava que o papel dessa modalidade na vida de uma criança era apenas o brincar, em um espaço onde o conhecimento era apresentado pela brincadeira, com direcionamento, mas sem preocupação pedagógica sobre a evolução da criança, de forma espontânea.

Para finalizar, no grupo focal, os professores concordaram que propor atividades que apresentam a história e a cultura dos diversos grupos que formam a sociedade humana é importante. Para professora "A": Os alunos precisam ampliar seus conhecimentos e saber de onde vieram suas raízes históricas e as diversidades culturais que existem". A professora "B" justificou que: "É direito da criança conhecer sua história e cultura de diversos grupos na sociedade. Porque conhecer é fundamental para respeitar. Por sua vez, a Professora "C" acrescentou que: "[...] demonstra empatia pelos outros, percebendo que as pessoas têm diferentes sentimentos, necessidades e modos de pensar e agir, o que faz parte dos objetivos de aprendizagem e desenvolvimento da criança.

Os professores consideram que é preciso inserir, no trabalho pedagógico, intervenções que estimulem reflexões sobre a história e cultura, dos diversos grupos que formaram a sociedade, justificando que é direito dos 
alunos conhecer suas raízes históricas e a diversidade cultural que configura nossa população.

A Lei $n^{\circ} 10.639 / 03$ e a Lei $n^{\circ} 11.645 / 08$ foram promulgadas, e as Diretrizes Educacionais Nacionais e a Lei de Diretrizes e Bases foram alteradas, respectivamente, para obrigatoriedade do ensino da cultura afrobrasileira e indígena. No que se refere a Lei $n^{0} 11.645 / 08$, a referida dispõe que:

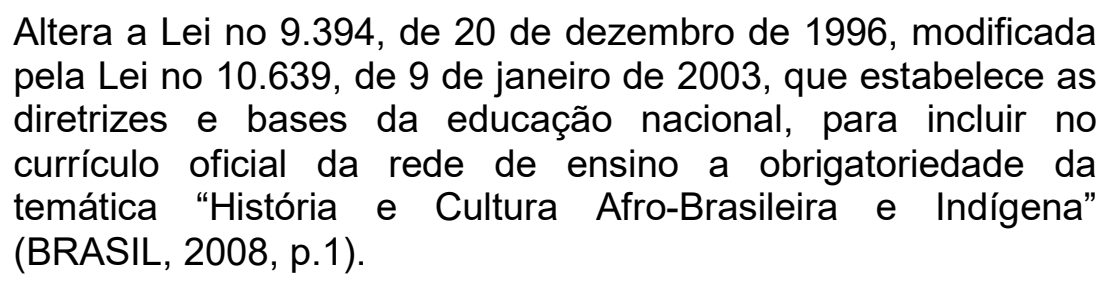

Para Pereira e colaboradores (2019), o estabelecimento de escolas de ensino fundamental e médio é o resultado de um grande processo de luta política e social, que representa o reconhecimento das pessoas sobre a de se abordar nos currículos infantis atividades que discutem a história e a cultura de grupos marginalizados, como os negros e indígenas. Tais atividades se expressam numa forma de reparação social pelos longos anos de danos de descaso pelas identidades e direitos, vividos nos processos de escravidão e a colonização e revividos em períodos até a história recente pela falta de políticas e de práticas educacionais inclusivas. Embora existam legislações que amparem essa reparação, as práticas realizadas no chão da escola, precisam de novas abordagens para atender a diversidade que compõe a sociedade brasileira.

Cada um tem seu jeito de pensar, sentir e agir, pois só por meio de práticas pedagógicas criativas assim as crianças saberão respeitar e valorizar a diversidade existente no país. Poderão, também, reduzir o preconceito e a discriminação. Nesse sentido, seguem as orientações das Diretrizes Curriculares Nacionais para a Educação Infantil, ao destacarem a obrigação da escola, de desenvolver atividades que abordem os aspectos históricos, culturais dos povos que compõem o Brasil (BRASIL, 2010). 


\section{Considerações finais}

A realização desse estudo permitiu compreender como as ferramentas lúdicas, como a modelagem de objetos da cultura indígena, potencializam o ensino de Artes na Educação Infantil, valorizando esta cultura. Nosso parâmetro para esta constatação foi a realização da pesquisa de campo com alunos e professores de duas turmas do $2^{\circ}$ Período, de uma escola de Educação Infantil do Município de Presidente Kennedy.

Os resultados apontados pela pesquisa levam a concluir que o ensino de Artes na educação infantil auxilia no desenvolvimento integral da criança, por desenvolver a imaginação, a sensibilidade, os movimentos e gestos, a criatividade, a socialização. As práticas lúdicas possibilitaram a expressão artística e a interação com os pares, levando os alunos a realizar releituras, debates, comentários, discussões sobre as produções manuais. Nesse sentido, as crianças passaram a perceber o mundo como parte de si, podendo até quem sabe, se tornarem futuros agentes transformadores, culminando na sensação de pertencimento e valorização da cultura indígena.

Em meio aos debates foi possível notar que os professores entendem a necessidade de desenvolver intervenções didáticas sobre a história e cultura dos povos que compõem a sociedade, por entender que esse é um direito da criança e só conhecendo suas raízes históricas poderão respeitar e valorizar a diversidade cultural.

Porém, o ensino de Artes na escola ainda apresenta fragilidades, como a falta de um trabalho pedagógico mais efetivo em relação à cultura indígena, pois se constata um trabalho pedagógico superficial, na qual, apenas são passadas as informações, sem utilização de uma proposta lúdica que contribua para o desenvolvimento da criança.

\section{Referências}

ARANTES, Adriana Rocha Vilela. BARBOSA, Jéssica Thaynara da Silva. O lúdico na educação infantil. Revista Magistro de Filosofia [online], Anápolis, ano X, n. 21, 1. semestre 2017. 
ARRUDA, Fabiane Santiago de. O lúdico enquanto artefato da prática pedagógica dos professores do Centro de Educação Infantil Carmelina Rios. 2016. 95 f. Dissertação (Mestrado Profissional em Gestão social, Educação e Desenvolvimento Regional) - Faculdade Vale do Cricaré, São Mateus-ES, 2016. em: <https://sucupira.capes.gov.br/sucupira/public/consultas/coleta/ trabalhoConclusao/viewTrabalhoConclusao.jsf?popup=true\&id_trabalho $=38953$ 05>. Acesso em: 26 ago. 2019.

BENTO, Cláudio Moreira. Os índios Puris do Vale do Paraíba paulista e fluminense. In: XII SIMPÓSIO DE HISTÓRIA DO VALE DO PARAIÍBA, 1995. Disponível em: <www.ahimtb.org.br/OS\%20INDIOS\%20PURIS\%20DO\%20VALE\%20DA\%20P ARAIBA\%20PAULISTA\%20E\%20FLUMINIENSE.pdf>. Acesso em: 01 mai. 2020.

BERGAMASCHI, Maria Aparecida. MEDEIROS, Juliana Schneider. História, memória e tradição na educação escolar indígena: o caso de uma escola Kaingang. Revista Brasileira de História. 2010, v. 30, n.60. Disponível em: https://www.scielo.br/scielo.php?script=sci arttext\&pid=S010201882010000200004. Acesso em: 7 ago. 2020.

BRASIL. Ministério da Educação. Diretrizes Curriculares Nacionais para a Educação Infantil. Brasília-DF, 2010.

- Ministério da Educação. Ensino fundamental de nove anos: orientações para a inclusão da criança de seis anos de idade. Brasília: Secretária de Educação Básica, 2007.

LEI No 11.645, DE 10 MARÇO DE 2008: Altera a Lei no 9.394, de 20 de dezembro de 1996, modificada pela Lei no 10.639, de 9 de janeiro de 2003, que estabelece as diretrizes e bases da educação nacional, para incluir no currículo oficial da rede de ensino a obrigatoriedade da temática "História e Cultura Afro-Brasileira e Indígena". Disponível em: http://www.planalto.gov.br/ccivil 03/ Ato2007-2010/2008/Lei/L11645.htm. Acesso em: 21 ago. 2020.

\footnotetext{
Ministério da Educação. Base Nacional Curricular Nacional Comum-BNCC, Brasília-DF, 2017. Disponível em: <http://basenacionalcomum.mec.gov.br/ \#/site/inicio>. Acesso em: 26 ago. 2019.
}

COLETO, Daniela Cristina. A importância da arte para a formação da criança. Revista Conteúdo, Capivari, v.1, n.3, jan./jul. 2010. Disponível em:

<http://www.conteudo.org.br/index.php/conteudo/article/viewFile/35/34>. Acesso em: 26 ago. 2019.

COLL, César. O construtivismo na sala de aula. São Paulo: Ática, 1998. 
VIANA, Simone Corassari. A importância do brincar na educação infantil: eixo movimento. Trabalho de Conclusão de Curso apresentado à Universidade Estadual de Londrina. 2015. Disponível em: < http://www.uel.br/ceca/pedagogia/pages/arquivos/2015\%20SIMONE\%20CORA SSARI\%20VIANA.pdf>. Acesso em: 26 ago. 2019.

CHIESA, Regina Fiorezzi. O diálogo com o barro: o encontro com o criativo. São Paulo: Casa do Psicólogo, 2004.

DIEHL, Viviane. Educação do sensível em artes visuais: modelando o barro e (re)significando o corpo. In: ANPAP, Anais...Florianópolis, n. 17, ago. 2008. Disponível em: <http://www.anpap.org. br/anais/2008/artigos/137.pdf>. Acesso em: 01 jun. 2018.

FILHO, João Baptista. A utilização de substâncias minerais pelos povos indígenas. Breves Comentários. Anuário do Instituto de Geociências-UFRJ, Rio de Janeiro, v. 22, 1999. Disponível em: <http://www.ppegeo.igc.usp.br/index.php/anigeo/ article/view/1784>. Acesso em: 20 fev. 2020.

GAIO, Rosilene Maria da Silva. Um olhar sobre educação infantil: e a Arte onde está? E o corpo como está? 2015. 144 f. Dissertação (Mestrado) Programa de Pós-Graduação em Educação Processos Socioeducativos e Práticas Escolares, Universidade Federal de São João del-Rei, Minas Gerais, $2015 . \quad$ Disponível em: <https://www.ufsj.edu.br/portal2repositorio/File/mestradoeducacao/Dissertacao $\% 20$ Rosilene\%20Maria\%20da\%20Silva\%20Gaio.pdf>. Acesso em: 26 ago. 2019.

GIANNOTTI, Sirlene. Dar forma é forma-se: processo criativos da arte para a infância. 2008. 235 f. Dissertação (Mestrado em Educação) - Faculdade de Educação de São Paulo, 2008. Disponível em: <https://teses.usp.br/teses/ disponiveis/48/48134/tde-26012009-

41434/publico/DissertacaoSirleneGiannotti.pdf>. Acesso em: 1 jun. 2018.

MENDES, Nelci Bento Garcia. Modelagem em argila com estudantes do nono ano do ensino fundamental: valorizando a cultura indígena. In: Os desafios da escola paranaense na perspectiva do professor PDE - Produções Didático-Pedagógicas, [online], v. II, Programa de Desenvolvimento Educacional - PDE, Governo do Estado do Paraná, 2016. Disponível em: $<$ http://www.diaadiaeducacao.pr.gov.br/portals/cadernospde/pdebusca/produco es_pde/2016/2016_artigo_arte_uel_nelcibentogarcia.pdf>. Acesso em: 26 ago. 2019.

OLIVEIRA, Alessandra Mara Rotta de. Escultura e imaginação infantil: um mar de história sem fim. 2008. 77 f. Tese (Doutorado em Educação) Universidade Federal de Santa Catarina, 2008. Disponível em: <http://www.grupodec.net.br/wp-content/uploads/20 15/10/tese-escultura.pdf>. Acesso em: 01 jun. 2018. 
PEREIRA, Arliene Stephanie Menezes. Et al. Aplicação das leis 10.639/03 e 11.645/08 nas aulas de educação física: diagnóstico da rede municipal de Fortaleza/CE. Revista Brasileira de Ciências do Esporte, 2019. v. 41, n. 4. Disponível em: https://www.scielo.br/scielo.php?pid=S010132892019000400412\&script=sci arttext\&tlng=pt. Acesso em: 19 ago. 2020.

POLO, Aparecida Tamiris. PEDRAÇA, Dulce Guimarães. A importância da educação infantil para o desenvolvimento pleno da criança. In: $15^{\circ}$ CONGRESSO NACIONAL DE INICIAÇÃO CIENTÍFICA, CONIC/SEMESP, Anais...Ribeirão Preto-SP, 27-28 nov. 2015. Disponível em: <http://conicsemesp.org.br/anais/files/2015/trabalho-1000021105.pdf.>. Acesso em: 12 set. 2019.

POMNITZ, Naila Cohen. O curso de pedagogia EAD a formação para atuação na educação infantil: o olhar dos sujeitos no âmbito das práticas. 2015. $134 \mathrm{f}$. Dissertação (Mestrado em Educação) - Universidade Federal de Santa Maria, UFSM. 2015.2 Disponível em: <https://sucupira.capes.gov.br/sucupira/public/consultas/coleta/trabalhoConclus ao/viewTrabalhoConclusao.jsf?popup=true\&id_trabalho=2712157>. Acesso em: 22 ago. 2019.

ROCHA, Marisa Lopes da. AGUIAR, Kátia Faria de. Pesquisa-intervenção e a produção de novas análises. Psicologia Ciência e Profissão, 2003, v. 23, n. 4, pp. 64-73. Disponível em: <http://pepsic.bvsalud.org/pdf/pcp/v23n4/v23n4a10.pdf>. Acesso em: 09 nov. 2019.

SANTANA, Katiane Cardoso. MATA, Áurea Augusta Rodrigues da. A importância da educação infantil para o desenvolvimento do indivíduo. In: III CONEDU- CONGRESSO NACIONAL DE EDUCAÇÃO. Anais...Natal-RN, 5-7 out. $2016 . \quad$ Disponível em: <http://www.editorarealize.com.br/revistas/conedu/trabalhos/TRABALHO_EV05 6_MD1_SA17_ID2022_09062016000008.pdf>. Acesso em: 01 jun. 2018.

SANTILIANO, Thiago Costa. Os índios Goitacases e Puris que habitavam nossa região. Geocosta, Mimoso do Sul-ES, 2014. Disponível em: <https://geocostan. webnode.com.br/historia/historia/indios-que-habitavamnossa-região/>. Acesso em: 01 mai. 2019.

VILLA, Denise Carla de. O corpo em contato com o barro: a educação do sensível no ensino das artes visuais. Unoesc \& Ciência - ACHS, Joaçaba, v. 4 , n. 1, p. 113-122, jan./jun. 2013. Disponível em: <https://editora.unoesc.edu.br/index.php/achs/ article/viewFile/2680/pdf. >. Acesso em: 01 jun. 2018.

VYGOTSKY, Lev Semyonovich. Pensamento e linguagem. São Paulo: Martins Fontes, 2000.

A Imaginação e a Arte na Infância. Madri: Akal, 2009. 
. LURIA, A. R. LEONTIEV, A.N. Linguagem, desenvolvimento e aprendizagem. 11. ed. São Paulo: Ícone, 2010.

\section{Sobre os Autores}

Soraia Jordão Souza

soeleo_24@hotmail.com

Possui graduação em Licenciatura em Artes pela Faculdade de Ciências Sociais de Cascavel (2015) e graduação em Ciências Biológicas pelo Centro Universitário São Camilo (2012). Atualmente é professora da Prefeitura Municipal de Presidente Kennedy. Tem experiência na área de Biologia Geral, com ênfase em Biologia Geral.

\section{Désirée Gonçalves Raggi}

desireeraggi@yahoo.com.br

Agronomia pela Universidade Federal de Viçosa. Mestrado em Pedagogia Profissional pelo Instituto Superior Pedagógico para la Educación Técnica e Profissional Hector P. Zaldivar / Universidade Federal de Goiás (2009). Doutorado em Educação - Universidad del Norte/ Universidade Federal de Pernambuco. Exerceu a docência em duas escolas agrotécnicas (Rio Verde GO e Alegre-ES) e no Instituto Federal do ES, na área de Educação. Atualmente é professora e pesquisadora da Faculdade Vale do Cricaré, 